\title{
Electroporation of Recombinant Proteins for in vivo Functional Studies in Cultured Mammalian Cells
}

Amal Alex ${ }^{1}$, Beate Voss ${ }^{1}$, Andrea Musacchio ${ }^{1,2}$ and Stefano Maffini ${ }^{1, *}$

\begin{abstract}
1Department of Mechanistic Cell Biology, Max Planck Institute of Molecular Physiology, Dortmund, Germany; ${ }^{2}$ Centre for Medical Biotechnology, Faculty of Biology, University Duisburg-Essen, Essen, Germany

*For correspondence: stefano.maffini@mpi-dortmund.mpg.de
\end{abstract}

[Abstract] Direct delivery of recombinant proteins into mammalian cells is an experimental approach that shows great potential for protein localization and function studies. Microinjection, which is currently the widely-used method for introducing recombinant proteins into mammalian cells, requires considerable handling skills and is a low-throughput approach limiting the delivery to a small number of targeted cells. On the other hand, high throughput delivery methods, like cell-penetrating peptide tags or pore-forming bacterial toxins, display uncertain protein uptake efficiencies and varying degrees of cytotoxicity. Here, we describe a protocol for batch electroporation (EP) which is suitable for the delivery of single polypeptides and multi-subunit protein complexes into mammalian cells. To perform EP, cells are harvested, washed and re-suspended in an electroporation buffer containing the diluted protein (called the "EP slurry"). The EP slurry is subjected to multiple electric pulses that create reversible ruptures in the cell's membrane and allow intracellular protein delivery. In our detailed study of the applications of the method, we show that EP displays homogenous uptake efficiency, semi-quantitative delivery of protein and rather low levels of cytotoxicity over multiple cell lines.

Keywords: Protein delivery, Live imaging, Fluorescent proteins, Cell biology, Biochemical reconstitution, Electroporation

[Background] Traditionally, microinjection is the most commonly used method for the introduction of recombinant proteins into mammalian cells (Komarova et al., 2007). This approach, even though it serves the purpose, has major limitations such as its low-throughput and the requirement of considerable handling skills. High-throughput approaches that enable protein delivery to a large number of cells are available, for instance the use of cell-penetrating peptide (CPP) tags (Inomata et al., 2009) or pore-forming bacterial toxins (Ogino et al., 2009; Teng et al., 2016), but present uncertainties with regard to protein uptake efficiencies and cytotoxicity. We extensively studied Batch Electroporation (EP) as a method for direct delivery of recombinant proteins into cultured human cells. The protocol that we describe does not demand advanced handling skills and it is easily and rapidly implemented. EP works efficiently on diverse mammalian cells, provides low cytotoxicity levels, homogenous uptake efficiencies between individual cells and it is semi-quantitative. We successfully employed EP as a delivery method for a number of cell biology applications (Alex et al., 2019). We observed that EP delivered recombinant proteins achieved native localization, physically interacted with endogenous binding partners and 
functionally complemented RNAi depleted endogenous complexes. EP is also suitable for live-cell spectroscopic applications such as FLIM-FRET microscopy or FRAP analysis. Moreover, EP can be used to introduce proteins with modified chemical handles or functional probes into cells and identify the elusive binding partners. Thus, in addition to its ease of application, EP is very attractive because it allows delivery in a sufficiently large cohort of cells and is therefore an ideal tool to bridge in vitro reconstitution and cell biology studies.

\section{Materials and Reagents}

1. $50 \mathrm{ml}$ conical Falcon tubes (Corning, Falcon, catalog number: 430290)

2. $15 \mathrm{ml}$ conical Falcon tubes (Corning, Falcon, catalog number: 352095 )

3. $1.5 \mathrm{ml}$ Eppendorf tubes (Sigma-Aldrich, Eppendorf, catalog number: Z66505-100EA)

4. Sterile individually packaged $5 \mathrm{ml}$ pipettes (Sigma-Aldrich, catalog number: SIAL1487)

5. Sterile individually packaged $10 \mathrm{ml}$ pipettes (Sigma-Aldrich, catalog number: SIAL1488)

6. 24 well imaging plate (Ibidi, catalog number: 82406)

7. Corning $10 \mathrm{~cm}$ cell culture dish (Sigma-Aldrich, catalog number: CLS430167)

8. HeLa cells

9. Purified protein of interest

10. Buffer R (included in Neon Transfection Kit, see Equipment section below)

11. FBS (Sigma-Aldrich, catalog number: TMS-013)

12. Penicillin, Streptomycin (GIBCO, catalog number: 15140122)

13. L-glutamine (GIBCO, catalog number: 25030081)

14. DMEM (Sigma-Aldrich, catalog number: D6429)

15. Phosphate Buffered Saline (PBS) (GE Healthcare, catalog number: SH30013.03) without calcium and magnesium

16. Trypsin EDTA (Sigma-Aldrich, catalog number: T4799)

17. $\mathrm{CO}_{2}$ independent imaging media (GIBCO, catalog number: 18045054)

18. $\mathrm{NaCl}$ (Sigma, catalog number: S9888-1KG)

19. $\mathrm{KCl}$ (Sigma, catalog number: $\mathrm{P} 3911-500 \mathrm{G}$ )

20. $\mathrm{Na}_{2} \mathrm{HPO}_{4}$ (Sigma, catalog number: S3264)

21. $\mathrm{KH}_{2} \mathrm{PO}_{4}$ (Sigma, catalog number: $\mathrm{P} 5655-500 \mathrm{G}$ )

22. $\mathrm{HCl}$ (Sigma)

23. HeLa Cell growth medium (see Recipes)

24. 1x PBS (see Recipes)

\section{Equipment}

1. Pipetman $P 20$ pipette (Gilson, catalog number: $F 123600$ )

2. Pipetman P200 pipette (Gilson, catalog number: F123601) 
3. Pipetman P1000 pipette (Gilson, catalog number: F123602)

4. Pipette boy (Corning, Falcon, catalog number: 357469)

5. Water bath (Julabo, model: ED (v.2))

6. Eppendorf centrifuge $5804 \mathrm{R}$ (Eppendorf, model: $5804 \mathrm{R}$, catalog number: 805000620)

7. Countess Cell Counter (Thermo-Fisher, catalog number: AMQAX1000)

8. Neon Transfection System (Invitrogen, catalog number: MPK5000S)

9. Neon Transfection $100 \mu \mathrm{l}$ Kit (Invitrogen, catalog number: MPK10025, this Kit includes also Buffer $\mathrm{R}$, which can not be purchased separately)

10. Deltavision Elite System (GE Healthcare)

11. Cell culture incubator with $\mathrm{CO}_{2}$ supply

12. Cell culture hood

\section{Procedure}

Electroporation (EP):

1. Culture the cells on $10 \mathrm{~cm}$ cell culture dishes until they reach the desired confluency, e.g., for HeLa cells we use $70-80 \%$ confluency.

2. Pre-warm $2.5 \%$ trypsin, the PBS and the growth culture medium without antibiotics to $37{ }^{\circ} \mathrm{C}$ prior to the experiment.

3. Remove the cell culture medium and wash the cells once with $5 \mathrm{ml}$ of PBS.

4. Detach the cells from the surface by incubating them with $1 \mathrm{ml}$ of $2.5 \%$ trypsin for $5 \mathrm{~min}$ at $37^{\circ} \mathrm{C}$.

5. Harvest the trypsinized cells and add to a $50 \mathrm{ml}$ tube and use warm PBS to bring the volume to $50 \mathrm{ml}$. Pellet the cells by centrifuging them at $500 \times g$ for $5 \mathrm{~min}$ at $25^{\circ} \mathrm{C}$.

6. Remove supernatant and resuspend the cells in approximately $1 \mathrm{ml}$ of PBS and count the cell number using the cell-counter Countess Cell Counter (Equipment number 7). Cell density should range between 2 and $8 \times 10^{6} \mathrm{cell} / \mathrm{s} / \mathrm{ml}$.

7. Transfer the volume of cell suspension needed for a final cell number between 1 and $3 \times 10^{6}$ cells to a 1.5-ml Eppendorf and pellet the cells by centrifuging them at $500 \times g$ for $5 \mathrm{~min}$.

8. Remove the PBS and resuspend the pellet to a final $90 \mu$ of resuspension buffer (buffer $R$ ). This suspension is called "EP slurry". It is important to proceed immediately with the EP, after this step. Cell viability could decrease significantly if the cells remain longer than 2 min in buffer-R. Buffer $\mathrm{R}$ is part of the EP kit from Invitrogen and its proprietary composition is unknown to the authors. We suggest to leave cell pellet in PBS and proceed at the resuspension in buffer $\mathrm{R}$ and $E P$ one sample at the time.

9. Dilute the recombinant purified protein 1:1 (volume:volume) in buffer $R$ and add $30 \mu \mathrm{l}$ of this suspension to the $90 \mu \mathrm{l}$ of EP slurry, for a final volume of $120 \mu \mathrm{l}$. Volumes and protein-buffer ratios may be adjusted according to the purpose of the experiment and depending on protein solubility. Final protein concentrations in the respective EP mixtures we tried varies between 5 and $200 \mu \mathrm{M}$. 
10. Load the EP mixture into a $100 \mu \mathrm{l}$ Neon Pipette Tip making sure to avoid bubble in the Neon tip while pipetting, as this will cause an electric short-circuit and kill the cells during EP.

11. Put the Neon pipette into the pipette station and electroporate the cells using the following: parameters:

Voltage: $1,000 \mathrm{~V}$

Number of pulses: 2

Time width of pulse: $35 \mathrm{~ms}$

12. Following the EP, add the EP-mixture to $15 \mathrm{ml}$ of pre-warmed PBS in a $15 \mathrm{ml}$ Falcon tube and centrifuge at $500 \times g$ for 5 mins.

13. Remove the PBS and add 3 to $7 \mathrm{ml}$ of Trypsin to the cell pellet (according to the pellet size) and incubate for $5 \mathrm{~min}$ at $37^{\circ} \mathrm{C}$. This step of trypsinization helps to remove non-internalized extracellular protein, and its timing needs to be adjusted on a protein-specific basis.

14. Make up the volume in the Falcon tube to $15 \mathrm{ml}$ using pre-warmed PBS and pellet the cells for $5 \mathrm{~min}$ at $500 \times \mathrm{g}$.

15. Remove the PBS and repeat the washing Step 13 two more times.

16. Resuspend the cell pellet in complete Imaging media (without antibiotics) and transfer to a cellimaging plate.

17. Keep the plate in $37^{\circ} \mathrm{C}$ incubator and allow the cells to recover for a minimum of $4 \mathrm{~h}$, until cells display adhesion and morphology state resemblying the pre-electroporation conditions.

18. After recovery, analyse the cells under a fluorescent microscope.

\section{$\underline{\text { Notes }}$}

1. This protocol is intended for the electroporation of a fluorescent protein into HeLa cells and observing the localization using fluorescence microscopy.

2. The quality of the recombinant protein sample is crucial for the success of this protocol. Samples should be monodispersed (i.e., following a Gel filtration purification step) and possibly pure.

3. The Neon transfection system and the corresponding Neon transduction kits are used for EP, but this procedure is also suitable for other electroporators, such as, for example, the Amaxa electroporator or the NEPA21 electroporator.

4. The volumes of buffers and protein mix described in this protocol refers to electroporations performed using the $100 \mu$ l Neon tip.

5. EP parameters need to be adjusted on a cell type specific basis, depending on the trade-off between efficiency of delivery and viability after EP.

\section{$\underline{\text { Recipes }}$}

1. HeLa Cell growth medium

Supplement DMEM with 10\% FBS, penicillin, streptomycin and $2 \mathrm{mM} \mathrm{L-glutamine}$ 
Store at $4{ }^{\circ} \mathrm{C}$

2. $1 \times$ PBS

For 10 liters of $1 \times$ PBS, resuspend one package of Phosphate Buffered Saline (PBS) powder (GE Healthcare) in a final volume of 10 liters of distilled water

\section{Acknowledgments}

We thank Melina Schuh and Dean Clift for discussion and comments. We are grateful to all members of the Selenko and Musacchio laboratories for reagents, helpful discussions and comments. A.M. gratefully acknowledges funding by the Max Planck Society and the European Research Council (ERC) Advanced Investigator Grant RECEPIANCE (proposal number: 669686).

\section{Competing interests}

All authors have no conflict of interest to declare.

\section{References}

1. Alex, A., Piano, V., Polley, S., Stuiver, M., Voss, S., Ciossani, G., Overlack, K., Voss, B., Wohlgemuth, S., Petrovic, A., Wu, Y., Selenko, P., Musacchio, A. and Maffini, S. (2019). Electroporated recombinant proteins as tools for in vivo functional complementation, imaging and chemical biology. Elife 8: e48287.

2. Inomata, K., Ohno, A., Tochio, H., Isogai, S., Tenno, T., Nakase, I., Takeuchi, T., Futaki, S., Ito, Y., Hiroaki, H. and Shirakawa, M. (2009). High-resolution multi-dimensional NMR spectroscopy of proteins in human cells. Nature 458(7234): 106-109.

3. Komarova, Y., Peloquin, J. and Borisy, G. (2007). Microinjection of protein samples. CSH Protoc 2007: pdb prot4657.

4. Ogino, S., Kubo, S., Umemoto, R., Huang, S., Nishida, N. and Shimada, I. (2009). Observation of NMR signals from proteins introduced into living mammalian cells by reversible membrane permeabilization using a pore-forming toxin, streptolysin O. J Am Chem Soc 131(31): 1083410835.

5. Teng, K. W., Ishitsuka, Y., Ren, P., Youn, Y., Deng, X., Ge, P., Lee, S. H., Belmont, A. S. and Selvin, P. R. (2016). Labeling proteins inside living cells using external fluorophores for microscopy. Elife 5: 20378. 